Case Report

\title{
Bilateral Radial Ulnar Synostosis and Vertebral Anomalies in a Child with a De Novo 16p13.3 Interstitial Deletion
}

\author{
Allison Tam, ${ }^{1,2}$ Kit Shan Lee, ${ }^{1}$ Sansan Lee, ${ }^{3}$ William Burkhalter, ${ }^{4,5,6}$ \\ Lucio U. Pascua, ${ }^{7}$ and Thomas P. Slavin ${ }^{3,4}$ \\ ${ }^{1}$ University of Hawaii, John A. Burns School of Medicine, Honolulu, HI 96813, USA \\ ${ }^{2}$ Hawaii Community Genetics, Ala Moana Building, 1441 Kapiolani Blvd, Suite 1800, Honolulu, HI 96814, USA \\ ${ }^{3}$ Kapiolani Medical Specialists, Hawaii Community Genetics, Honolulu, HI 96814, USA \\ ${ }^{4}$ Department of Pediatrics, University of Hawaii, John A. Burns School of Medicine, Honolulu, HI 96826, USA \\ ${ }^{5}$ Department of Surgery, University of Hawaii, John A. Burns School of Medicine, Honolulu, HI 96813, USA \\ ${ }^{6}$ Kapiolani Medical Specialists, Kapiolani Orthopedic Associates, Honolulu, HI 96826, USA \\ ${ }^{7}$ Department of Family Medicine, University of Hawaii, John A. Burns School of Medicine, Honolulu, HI 96789, USA
}

Correspondence should be addressed to Allison Tam; allison.c.tam@gmail.com

Received 16 May 2013; Accepted 13 June 2013

Academic Editors: D. J. Bunyan, C.-W. Cheng, P. D. Cotter, A. DeWan, and X. Wang

Copyright (C) 2013 Allison Tam et al. This is an open access article distributed under the Creative Commons Attribution License, which permits unrestricted use, distribution, and reproduction in any medium, provided the original work is properly cited.

\begin{abstract}
We describe an 8-year-old boy with developmental delay, clinical bilateral radial ulnar synostosis, Klippel-Feil anomaly, and other vertebral deformities who was found to have a de novo deletion of $114.5 \mathrm{~kb}$ at $16 \mathrm{p} 13.3$. The deletion contains five genes and three miRNAs. The genes are E4F1, DNASE1L2, ECI1, RNPS1, and ABCA3; miRNAs are MIR3677, MIR940, and MIR4717. The specific deletion has never been previously reported. We describe the phenotype of the boy and review the genes in the deleted region. None of the regulatory elements have any known linkage to skeletal formation and/or maintenance. We believe this deletion is causative given that it was de novo and that this patient cannot be easily explained as having any other specific recognizable pattern of human malformation.
\end{abstract}

\section{Introduction}

Many of the reports on chromosome 16p13.3 gene deletions are in relation to the Rubinstein-Taybi syndrome, alpha thalassemia mental retardation, polycystic kidney disease, and familial Mediterranean fever. Chromosome 16p13.3 gene deletions associated with the Rubinstein-Taybi syndrome are discussed in depth in articles by Wallerstein et al. and Hennekam et al., respectively $[1,2]$. We report a child with developmental delay, bilateral radial ulnar synostosis, Klippel-Feil anomaly, and other vertebral deformities with a de novo interstitial deletion of $114.5 \mathrm{~kb}$ on chromosome $16 \mathrm{p}$ found using chromosomal microarray. The deleted region contains five genes and three miRNAs of unclear clinical significance. We are not aware of reports of gene deletions that overlap with the $114.5 \mathrm{~kb}$ deletion described here. The purpose of this paper is to describe our patient's unique phenotype and discuss the possible genotype-phenotype correlations of the deleted region.

\section{Clinical Report}

Past medical history was significant for term birth with complication of preeclampsia of unknown etiology. He had no neonatal complications. His birth weight was $7 \mathrm{lbs} 3 \mathrm{oz}$. Family history was unremarkable for skeletal disorders. Younger full sibling sister was healthy without issues. The patient had a history of developmental delay and was in an early intervention program in California. He walked around age 2, spoke at age 3 , and had phrases around age 4 . He also was not toilet trained until age 4 . Neurodevelopmental assessment at the age of 8 years showed a Wechsler Intelligence Scale for Children Fourth Edition (WISC IV) verbal comprehension of 89 , working memory of 80 , perceptional reasoning of 96 , 


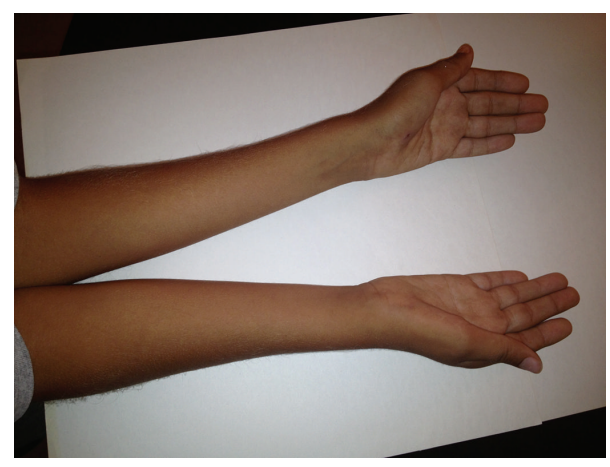

(a)

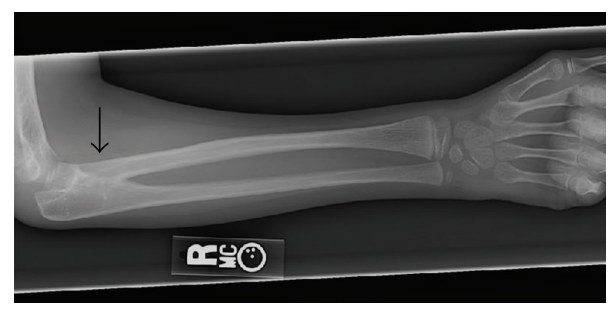

(b)

FIGURE 1: Photograph showing the patient's forearm with limitation of rotation (a). There is also hypoplasia of the thenar and hypothenar muscular prominences of his hands bilaterally. Radiograph of the right forearm (b). The arrow indicates the site of bony synostosis.

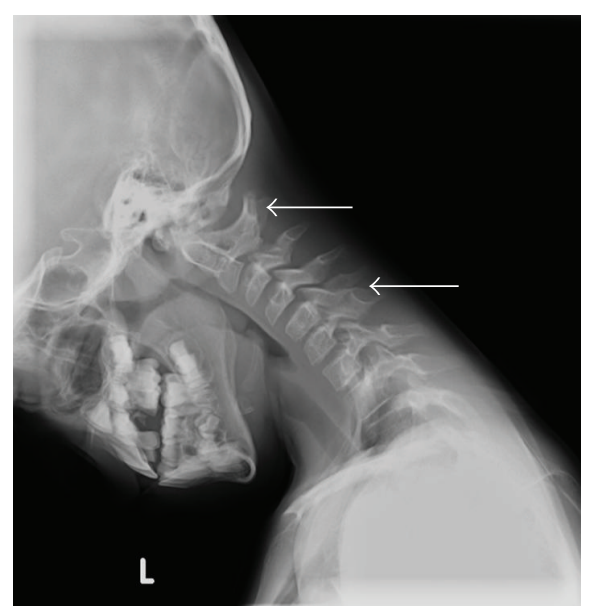

FIGURE 2: Radiograph depicting the Klippel-Feil anomaly with partial fusion of the posterior elements of C1-2 and C5-6 (arrows). Note also that there are 8 cervical vertebrae.

processing speed of 83 , and low average full scale IQ of 84 . He had a history of two febrile seizures, one at age 2 and one at age 6 . The patient had no history of hospitalizations or surgeries.

The patient's mother noted unusual arm positioning since birth. At the age of 7 the patient was referred to an orthopedist and was found to have bilateral radial ulnar synostosis by clinical exam (Figure 1(a)). Congenital fusions were also noted on cervical spine radiographs (Figure 2) obtained for restricted neck motion noted incidentally on

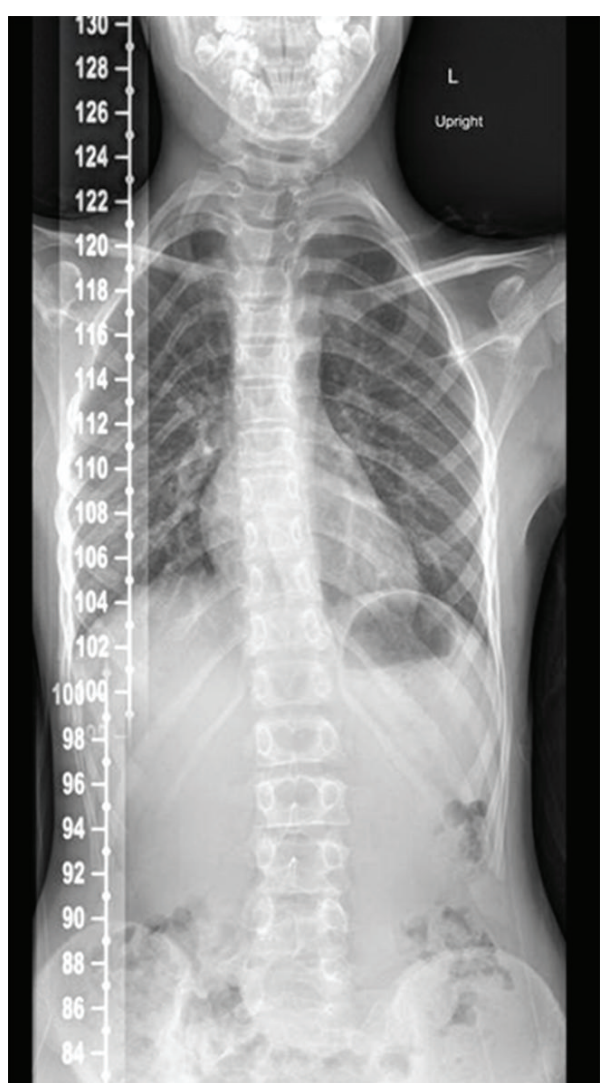

FIGURE 3: Chest radiograph from patient, showing 13 sets of ribs and "S" shaped scoliosis with 11-degree thoracic dextroconvex and 8-degree lumbar levoconvex scoliosis.

physical examination. Plain radiographs of the right elbow revealed trochlear dysplasia and complete radial ulnar synostosis (Figure 1(a)). Dysplasia of the proximal radio-ulnar articulation was noted on the left leading to an incomplete, yet functionally nearly complete, synostosis. A true left bony synostosis was not confirmed on CT scan, although MRI was not completed to better define the fibrous ligament attachments. Radiographic assessment of the cervical spine was notable for eight cervical vertebrae and the Klippel-Feil anomaly with congenital fusions at $\mathrm{Cl}-2$ and $\mathrm{C} 5-6$. Imaging of the entire spine revealed other vertebral abnormalities including "S" shaped scoliosis with 11-degree thoracic dextroconvex and 8-degree lumbar levoconvex scoliosis, absence of the right pedicle at L5 with abnormal articulation with the sacrum, and 13 sets of ribs (Figure 3).

At his initial genetics diagnostic evaluation at age 8 , he measured $132.1 \mathrm{~cm}$ tall (75th percentile), weighed $23.12 \mathrm{~kg}$ (25th percentile), and his head circumference was $51.5 \mathrm{~cm}$ (20th percentile). He had nondysmorphic, but myopathic, facial features with a small jaw. His mouth displayed dental crowding with ankyloglossia, a large thick tongue, and a bifid uvula. He had prominent ear crus bilaterally. He had wide nipple spacing with the nipples being on the lateral aspect of his clavicles. He displayed limited range of motion in his neck, mild scoliosis, complete loss of forearm rotation on 
TABLE 1: Deleted elements in the region with associated known function.

\begin{tabular}{|c|c|}
\hline Deleted elements & Function \\
\hline E4F1 & $\begin{array}{l}\text { E4F transcription factor } 1 \text { is involved in the regulation of cell growth, survival, and/or differentiation } \\
\text { [3]. Knockout mice studies suggest that E4F1 is crucial during early embryonic cell cycles and functions } \\
\text { in mitosis [4]. Relatively high expression in peripheral blood-CD4+ T cells, heart, lungs, liver, and } \\
\text { thymus [5] }\end{array}$ \\
\hline DNASEIL2 & $\begin{array}{l}\text { Deoxyribonuclease I- like 2, has strong endonuclease activity in the presence of certain cations, } \\
\text { including CA2+ and } \mathrm{Mg} 2+[6] \text {. Relatively high expression in pancreatic islets, liver, and bone marrow } \\
\text { [5] }\end{array}$ \\
\hline ECI1 & $\begin{array}{l}\text { Dodecenoyl-coenzyme A delta-isomerase encodes an isomerase that is involved in the mitochondrial } \\
\text { beta-oxidation of unsaturated fatty acids [7]. It has relatively high expression in heart, lungs, liver, } \\
\text { kidneys, thymus, and whole brain [5] }\end{array}$ \\
\hline RNPS1 & $\begin{array}{l}\text { RNA-binding protein } \mathrm{S} 1 \text { is a serine-rich RNA binding protein involved in alternative splicing and } \\
\text { regulation of physiological and developmental gene expression. It has been found in spliceosomes that } \\
\text { trigger nonsense-mediated decay, which is thought to be involved in mRNA surveillance. RNPS1 is } \\
\text { mainly expressed in hematologic cell lines [5] }\end{array}$ \\
\hline$A B C A 3$ & $\begin{array}{l}\text { An ATP-binding cassette family member that is homologous to the studied Caenorhabditis elegans } \\
\text { protein ced7. Involved in programmed cell death and expressed during embryogenesis. ABCA3 is } \\
\text { highly expressed in lung, brain, pancreas, skeletal muscle, and heart and is known to play an important } \\
\text { role in the formation of surfactant [5]. Homozygous mutations in ABCA3 have been shown in a cohort } \\
\text { of patient with severe neonatal respiratory distress and surfactant deficiency [8] }\end{array}$ \\
\hline MIR3677 & A short novel noncoding RNA involved in posttranscriptional regulation. Little known function [5] \\
\hline MIR4717 & A short novel noncoding RNA involved in posttranscriptional regulation. Little known function [5] \\
\hline MIR940 & $\begin{array}{l}\text { A short novel noncoding RNA involved in posttranscriptional regulation. Little known function. } \\
\text { Reported expression in renal cell carcinoma [9] }\end{array}$ \\
\hline
\end{tabular}

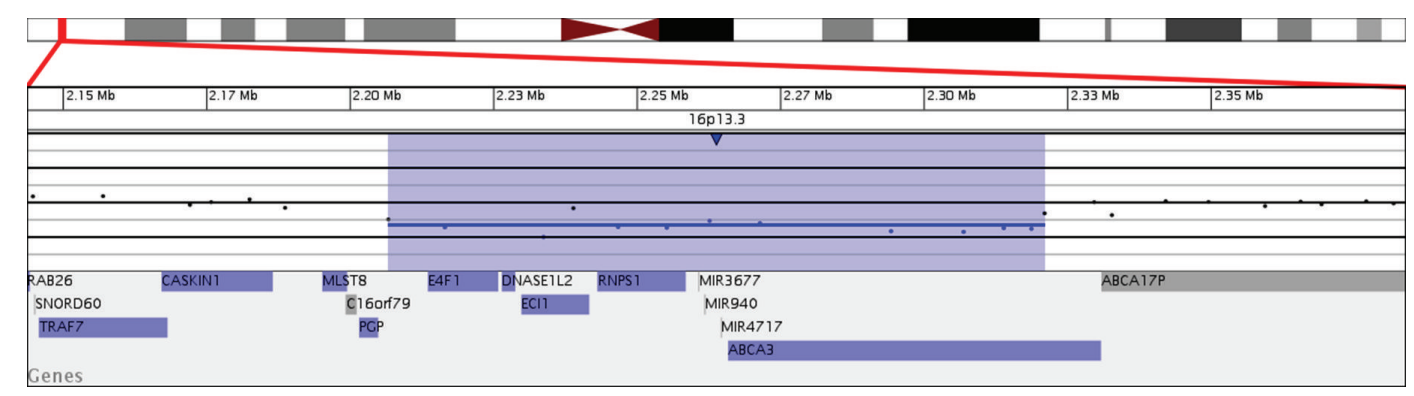

Figure 4: Microarray characterization of the 16p13.3 deletion described herein. Microarray plot showing single-copy loss of 13 oligonucleotide probes from 16p13.3, approximately $114 \mathrm{~kb}$ in size (chr16:2,206,663-2,321,155, hg18 coordinates). Probes are ordered on the $x$-axis according to physical mapping positions, with the most distal 16p13.3 probes to the left and the most proximal 16p13.3 probes to the right. Values along the $y$-axis represent $\log _{2}$ ratios of patient: control signal intensities. Results are visualized using Genoglyphix (Signature Genomics, Spokane, WA, USA).

the right and limited pronation and supination on the left. He had a right transverse single palmar crease. He displayed hypoplasia of thenar and hypothenar musculature bilaterally (Figure 1). He had some prominence of the medial aspect to the top of his knees. His gait was uncoordinated and he was unable to run. The remainder of his physical exam was unremarkable. A renal ultrasound was normal. Full skeletal survey and echocardiogram were recommended but not done at the time of this report.

\section{Cytogenetics and Molecular Studies}

Signature Genomic Laboratories, SignatureChiOS(Tm), version 2, $135 \mathrm{~K}$ microarray (Spokane, WA, USA) completed on blood showed a $114.5 \mathrm{~Kb}$ interstitial deletion, arr 16p13.3(2, 206,663-2,321,155) × 1 dn (based on UCSC hg18 assembly) (Figure 4). Fluorescence in situ hybridization (FISH) analysis of interphase nuclei using a BAC clone from the deleted region confirmed a deletion, ish $\operatorname{del}(16)$ p13.3p13.3)(RP11657D15-) dn. Parental analyses were performed and neither parent was found to carry a deletion or rearrangement of the $16 \mathrm{p} 13.3$ region. Thus the deletion identified in this patient was apparently de novo in origin. The deletion contains five genes and three miRNAs. The genes are E4F1, DNASE1L2, ECI1, RNPS1, and ABCA3; miRNAs are MIR3677, MIR940, and MIR4717 (Table 1). Complete blood count was normal and Fanconi's anemia testing by chromosome breakage was normal. 


\section{Discussion}

A recent case report by Nelson et al. described a boy with a de novo 16p13.3 deletion with multiple congenital anomalies including tracheobronchomalacia, CT-proven metopic craniosynostosis, glandular hypospadias with severe ventral chordee, torticollis, esotropia, strabismus, fifth finger clinodactyly, hallux valgus, and global developmental delay [10]. He was found to have a de novo $555 \mathrm{~Kb}$ deletion at $16 \mathrm{p} 13.3$ deletion (chr16:2,716.773-3,271,348), which encompassed 25 known genes. This deletion does not overlap with the deleted segment described in this paper. Therefore, no clear link can be made between the bony abnormalities in the patient presented herein and the metopic craniosynostosis described by Nelson et al. [10].

Interestingly, none of the deleted elements have any known involvement with skeletal regulation to explain the striking bony defects seen in the patient presented herein. E4F1, DNASEIL2, and RNPS1 are expressed in bone marrow and hematologic cell lines and have broad functions and therefore may have a role in bone regulation. ECI1, involved in beta-oxidation of unsaturated fatty acids, could be contributing to the patient's mild cognitive impairment; however, this seems unlikely given the absence of developmental regression or metabolic crises. $A B C A 3$, involved in surfactant production, is the only gene in this region with a reported phenotype (Table 1). ECI1 and ABCA3 would only be expected to cause disease in an autosomal recessive fashion, likely explaining the lack of any history of neonatal respiratory distress syndrome and/or metabolic disease.

Nonetheless, even though we cannot find a specific genotype-phenotype correlation to explain the bony findings in this patient, our findings are suggestive that this deletion is causative. The deletion was de novo and the patient does not fit any other syndromic phenotype besides Fanconi's anemia, which we completed testing for. We are not clinically working this child up for any other suspected condition. A sporadic birth defect could be a possible explanation; however, it would be unusual to involve only separate elements of the skeletal system. The deletion could be inducing positional effects in the region, thus affecting other genes in the surrounding area. Also, the miRNAs could be involved in bone remolding, or other bone regulatory abnormalities may have been unmasked from previously unknown recessive effects from the haploinsufficiency in the region. As this is the first case report involving this particular gene deletion, additional case reports and functional studies regarding the genes and regulatory elements contained in this region will be valuable in better understanding their role in skeletal regulation.

\section{Acknowledgments}

The authors would like to acknowledge the patient and his family for their kind cooperation, as well as all clinical and laboratory personnel involved in his care. In addition, they especially appreciate Signature Genomics Laboratories help with providing the probe intensity figure.

\section{References}

[1] R. Wallerstein, C. E. Andersen, B. Hay et al., "Submicroscopic deletions at 16p13.3 in Rubinstein-Taybi syndrome: frequency and clinical manifestations in a North American population," Journal of Medical Genetics, vol. 34, no. 3, pp. 203-206, 1997.

[2] R. C. M. Hennekam, M. Tilanus, B. C. J. Hamel et al., "Deletion at chromosome 16p13.3 as a cause of Rubinstein-Taybi syndrome: clinical aspects," The American Journal of Human Genetics, vol. 52, no. 2, pp. 255-262, 1993.

[3] R. J. Rooney, R. R. Daniels, N. A. Jenkins et al., "Chromosomal location and tissue expression of the gene encoding the adenovirus E1A-regulated transcription factor E4F in humans and mice," Mammalian Genome, vol. 9, no. 4, pp. 320-323, 1998.

[4] L. le Cam, M. Lacroix, M. A. Ciemerych, C. Sardet, and P. Sicinski, "The E4F protein is required for mitotic progression during embryonic cell cycles," Molecular and Cellular Biology, vol. 24, no. 14, pp. 6467-6475, 2004.

[5] W. J. Kent, C. W. Sugnet, T. S. Furey et al., "The human genome browser at UCSC," Genome Research, vol. 12, no. 6, pp. 9961006, 2002.

[6] A. M. Rodriguez, D. Rodin, H. Nomura, C. C. Morton, S. Weremowicz, and M. C. Schneider, "Identification, localization, and expression of two novel human genes similar to deoxyribonuclease I," Genomics, vol. 42, no. 3, pp. 507-513, 1997.

[7] U. Janssen, T. Fink, P. Lichter, and W. Stoffel, "Human mitochondrial 3,2-trans-enoyl-CoA isomerase (DCI): gene structure and localization to chromosome 16p13.3," Genomics, vol. 23, no. 1, pp. 223-228, 1994.

[8] S. Shulenin, L. M. Nogee, T. Annilo, S. E. Wert, J. A. Whitsett, and M. Dean, "ABCA3 Gene Mutations in Newborns with Fatal Surfactant Deficiency," New England Journal of Medicine, vol. 350, no. 13, pp. 1296-1303, 2004.

[9] W.-O. Lui, N. Pourmand, B. K. Patterson, and A. Fire, "Patterns of known and novel small RNAs in human cervical cancer," Cancer Research, vol. 67, no. 13, pp. 6031-6043, 2007.

[10] M. Nelson, S. Quinonez, T. Ackley, R. K. Iyer, and J. W. Innis, "Multiple congenital anomalies and developmental delay in a boy associated with a de novo 16p13.3 deletion," American Journal of Medical Genetics, Part A, vol. 155, no. 3, pp. 612-617, 2011. 


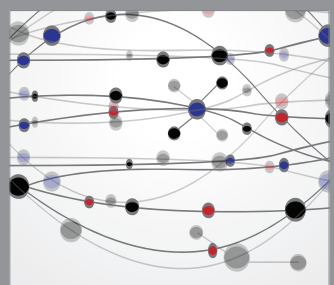

The Scientific World Journal
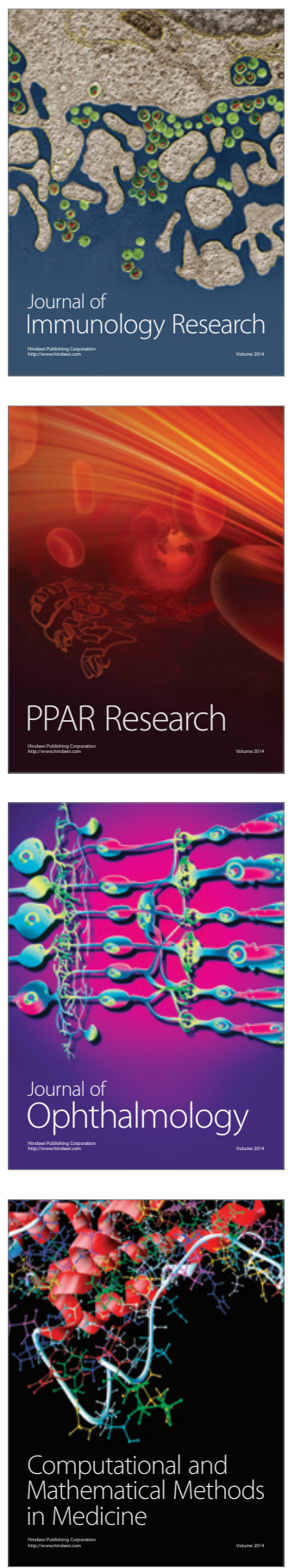

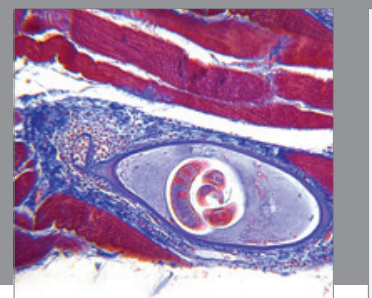

Gastroenterology

Research and Practice
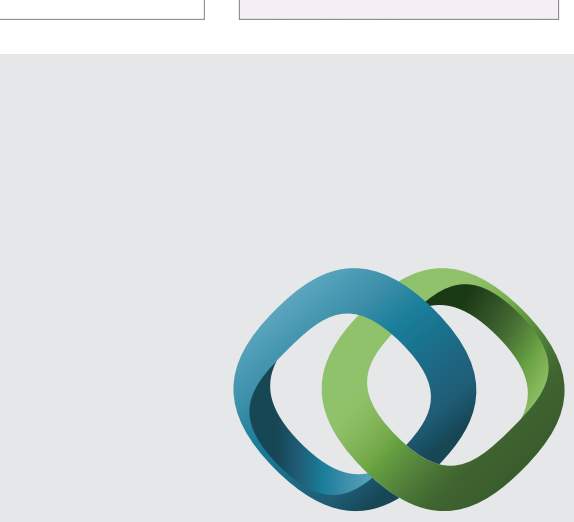

\section{Hindawi}

Submit your manuscripts at

http://www.hindawi.com
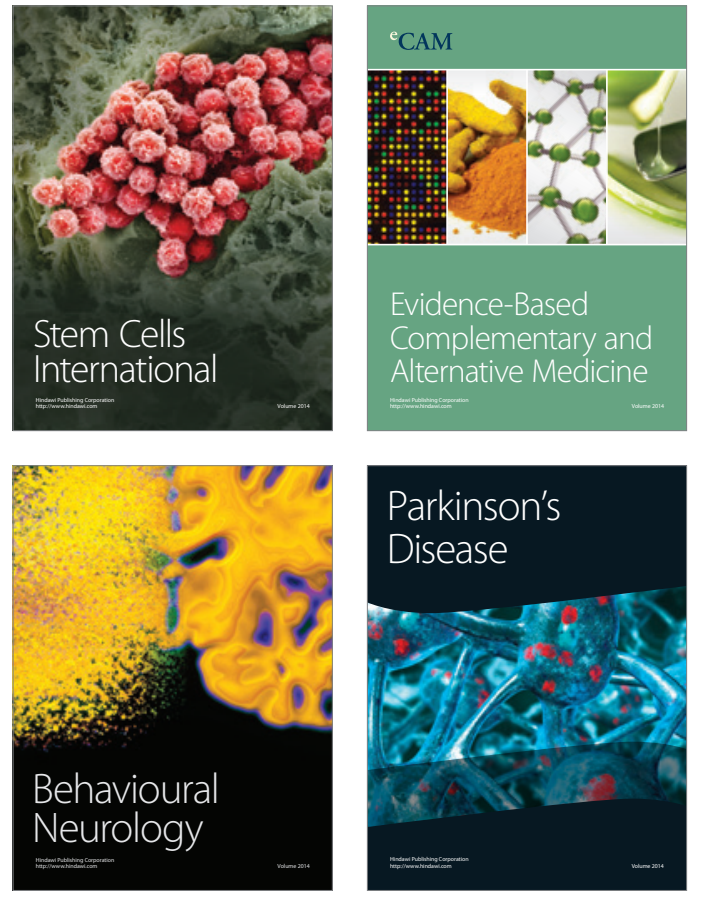
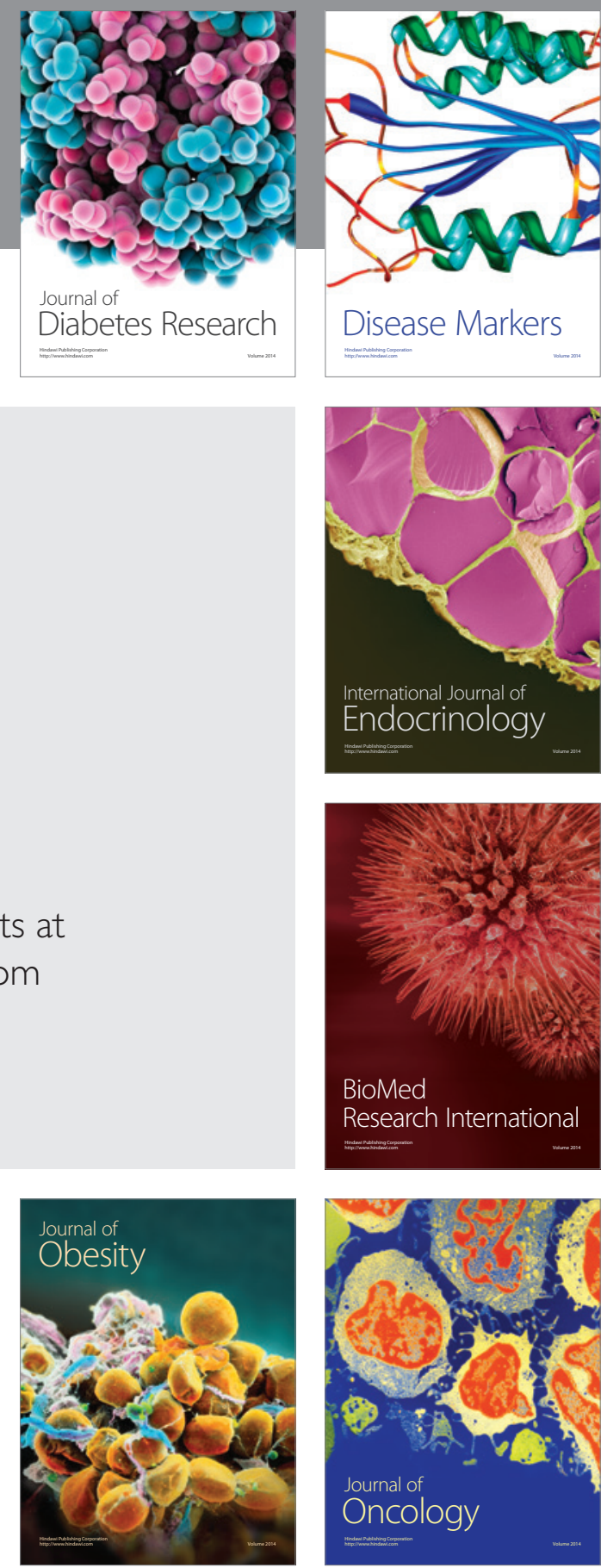

Disease Markers
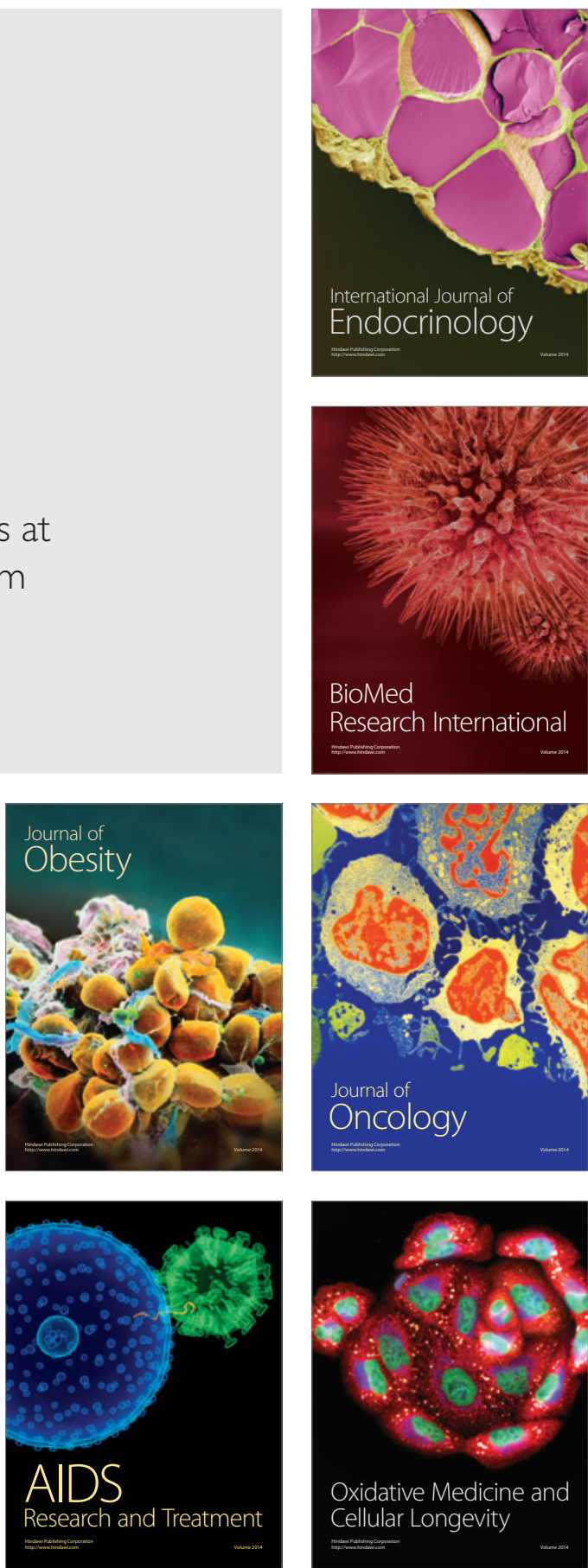